\title{
Port-access redo mitral valve surgery in a 13-year-old child
}

\author{
Davide Ricci, MD, ${ }^{\mathrm{a}, \mathrm{b}}$ Cristina Barbero, MD, ${ }^{\mathrm{a}}$ Massimo Boffini, MD, ${ }^{\mathrm{a}}$ Suad El Qarra, MD, ${ }^{\mathrm{a}}$ \\ Francesca Ivaldi, MD, ${ }^{\mathrm{a}}$ Luca Deorsola, MD,${ }^{\mathrm{c}}$ Carlo Pace, $\mathrm{MD},{ }^{\mathrm{c}}$ and Mauro Rinaldi, MD, ${ }^{\mathrm{a}}$ Turin and \\ Pavia, Italy
}

The case of a 13-year-old child (weight, $38 \mathrm{~kg}$; height, $150 \mathrm{~cm}$; body surface area, $1.23 \mathrm{~m}^{2}$; body mass index, $16.9 \mathrm{~kg} / \mathrm{m}^{2}$ ), undergoing mitral prosthesis replacement through a minithoracotomy using the port-access platform, ${ }^{1,2}$ is reported. The patient had undergone 3 previous cardiac surgeries.

At the age of 8 months, the patient underwent correction of an anomalous left coronary artery originating from the pulmonary artery trunk with the Takeuchi procedure, and a mitral valve repair with the Kay technique. At 2 years of age, he underwent reoperation for a posterior leaflet extension with a pericardial patch as a result of severe mitral regurgitation. A few months later the mitral valve was replaced with a mechanical prosthesis $(17 \mathrm{~mm}$; St Jude Medical, St Paul, Minn) for severe residual insufficiency. All previous procedures were performed through a longitudinal median sternotomy. At 13 years of age, the patient came to our attention for onset and worsening of dyspnea (New York Heart Association class II-III). Upon physical examination, a diastolic precordial murmur was found. A mean gradient of $12 \mathrm{~mm} \mathrm{Hg}$ was measured by transthoracic echocardiography with normal movement of both prosthesis disks.

Given these echocardiographic findings and symptoms, the indication for mitral prosthesis replacement was confirmed. Feasibility, safety, and efficacy of redo cardiac surgeries in adults using a mini-invasive port-access platform has been reported previously by many investigators, ${ }^{2-4}$ but the application of this approach to small children rarely has been described. ${ }^{5}$ Mini-invasive approaches, especially in reoperations, bear the disadvantage of femoral venous and arterial cannulation. This can be a serious problem in the case of small vessels, such as in pediatric patients.

\footnotetext{
From the Department of Cardiovascular and Thoracic Surgery, ${ }^{a}$ San Giovanni Hospital "Molinette" and Department of Pediatrics, ${ }^{c}$ Pediatric Cardiac Surgery Division, Children's Regina Margherita Hospital, University of Turin, Turin; and Department of Surgery, ${ }^{\mathrm{b}}$ Dipartimento di Scienze Chirurgiche, Rianimatorie-Riabilitative e dei Trapianti d'Organo, Fondazione IRCCS "San Matteo" Hospital, University of Pavia, Pavia, Italy.

Disclosures: Dr Rinaldi reports lecture fees from Novartis and Edwards Lifesciences. The other authors have nothing to disclose with regard to commercial support.

Received for publication May 27, 2013; revisions received June 15, 2013; accepted for publication June 21, 2013; available ahead of print July 22, 2013.

Address for reprints: Davide Ricci, MD, Department of Cardiovascular and Thoracic Surgery, San Giovanni Hospital "Molinette," University of Turin, Corso Bramante 88, 10126 Torino, Italy (E-mail: daveri@libero.it).

J Thorac Cardiovasc Surg 2013;146:e33-5

$0022-5223 / \$ 36.00$

Copyright (C) 2013 by The American Association for Thoracic Surgery

http://dx.doi.org/10.1016/j.jtcvs.2013.06.024
}

In this particular case, considering the patient's previous surgical history, transthoracic aortic cross-clamping was not possible. Ventricular fibrillation with an unclamped ascending aorta was an option. Nevertheless, there is evidence of increased neurologic events in adults after fibrillatory heart surgery, independently correlated with a minithoracotomy. For these reasons we explored the possibility of aortic clamping with a peripheral endoaortic balloon catheter, as we routinely do in adults.

A precise and detailed evaluation of the aortic-iliac and femoral vessels was performed. In particular, the femoral artery size (right, $6.0 \mathrm{~mm}$, Figure 1, $A$; left, $6.6 \mathrm{~mm}$, Figure 1, $B)$, the diameter of the ascending aorta $(22 \mathrm{~mm})$, and the distance between the origin of the left coronary artery, which was more cranial than usual because of the previous Takeuchi procedure, and the brachiocephalic artery $(31 \mathrm{~mm}$, Figure $1, C$ ) were measured using computed tomography scan and magnetic resonance imaging (Figure 1,D). Measurements were obtained to ascertain the possibility of performing endoaortic clamping and to identify the correct position of where to inflate the balloon, avoiding the obstruction of the left coronary artery or of the anonimus trunk. In this case the space for balloon inflation was $31 \mathrm{~mm}$. Safe endoclamping was achieved by inflating the balloon with $20 \mathrm{~mL}$ of saline solution, corresponding roughly to a diameter of $25 \mathrm{~mm}$ according to company in vitro tests (Figure 2).

Venous drainage was obtained with double jugular and femoral vein cannulation. The jugular venous cannula (14F DLP cannula; Medtronic, Minneapolis, Minn) was placed percutaneously whereas the femoral cannula (19Fr BioMedicus, Medtronic) was inserted through the groin incision. In both cases cannulation was performed with the Seldinger technique and the correct position was assessed under transesophageal echocardiogram control. The right femoral artery was cannulated with a $21 \mathrm{~F}$ arterial Y-cannula (EndoReturn; Edwards Lifesciences, Irvine, Calif) and the endoclamping balloon was placed before starting the cardiopulmonary bypass. Correct positioning of the balloon was confirmed under transesophageal echocardiogram guidance. Endoaortic clamping was achieved by inflating the balloon with approximately $20 \mathrm{~mL}$ of saline solution and keeping the pressure of the balloon between 350 and $450 \mathrm{~mm} \mathrm{Hg}$. Cardioplegia ( $\mathrm{St}$ Thomas solution) was delivered directly from the tip of the balloon catheter into the aortic root after an adenosine bolus. No mechanical dysfunction of the previous St Jude $(17 \mathrm{~mm})$ prosthesis was detected. After removal, a 21-mm St Jude 

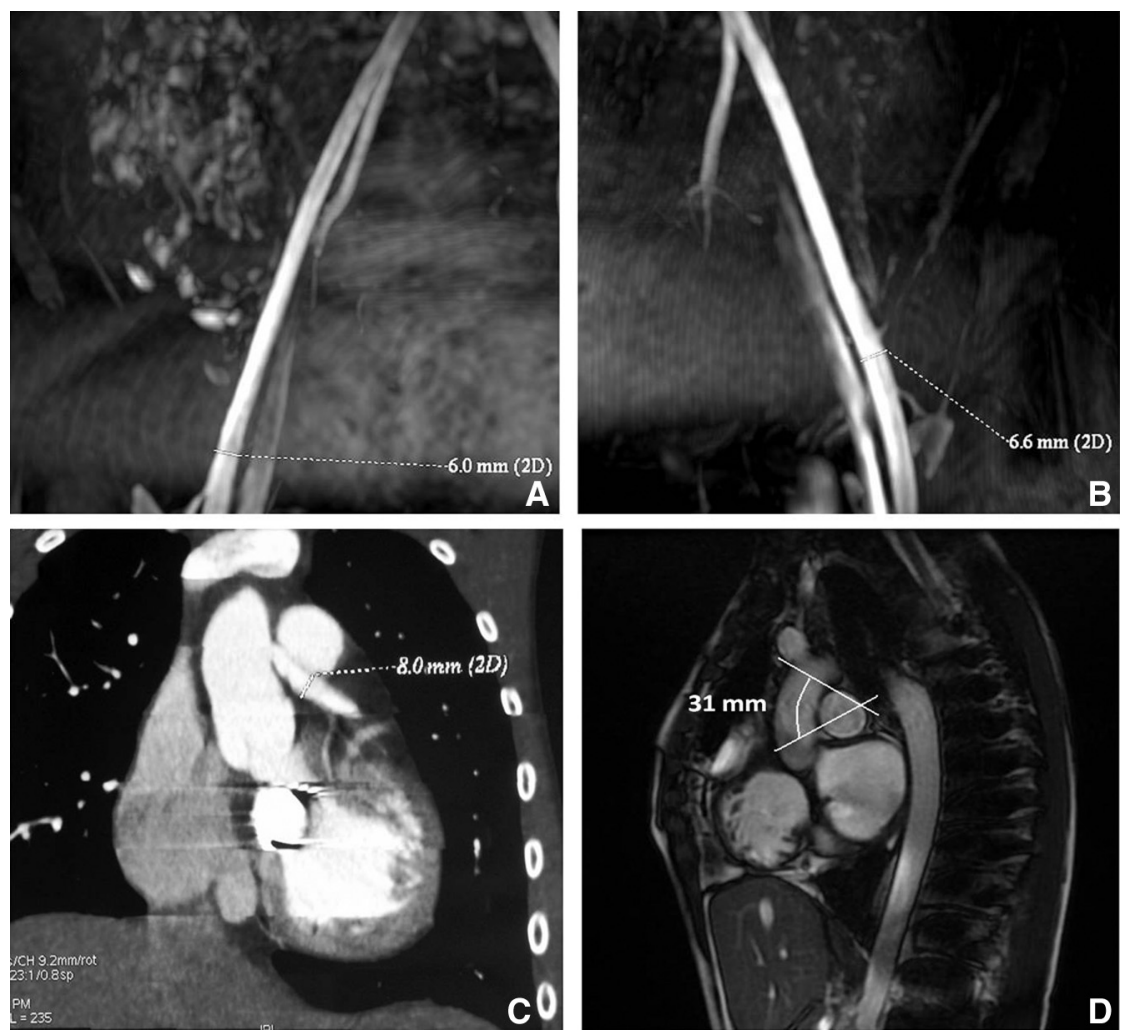

FIGURE 1. Bilateral femoral artery measurement with magnetic resonance imaging. A, Right femoral artery ( $6.0 \mathrm{~mm}), \mathrm{B}$, left femoral artery (6.6 mm), and $\mathrm{C}$, anteroposterior view of the heart and the ascending aorta on the computed tomography scan. The result of the Takeuchi procedure (left coronary to aortic tunnel with pulmonary artery baffle) is shown and measured $(8 \mathrm{~mm})$. D, Magnetic resonance image lateral view showing the aortic measurements: distance between the left coronary artery ostium after Takeuchi surgery and the innominate artery origin $(31 \mathrm{~mm})$.

mechanical prosthesis was implanted with singular $\mathrm{U}$ stitches with pledgets on the ventricular side.

The patient had an uneventful recovery. At the 15-month follow-up evaluation he was asymptomatic with echocardiographic evidence of normal mitral prosthesis function and no paravalvular leak.
This article shows that a minimally invasive surgical approach through a right anterolateral minithoracotomy using videoscopic assistance and endoclamping allows, even in children, performance of uncomplicated mitral valve procedures, avoiding a re-entry sternotomy with the associated risk of cardiac injury. In particular, tips and

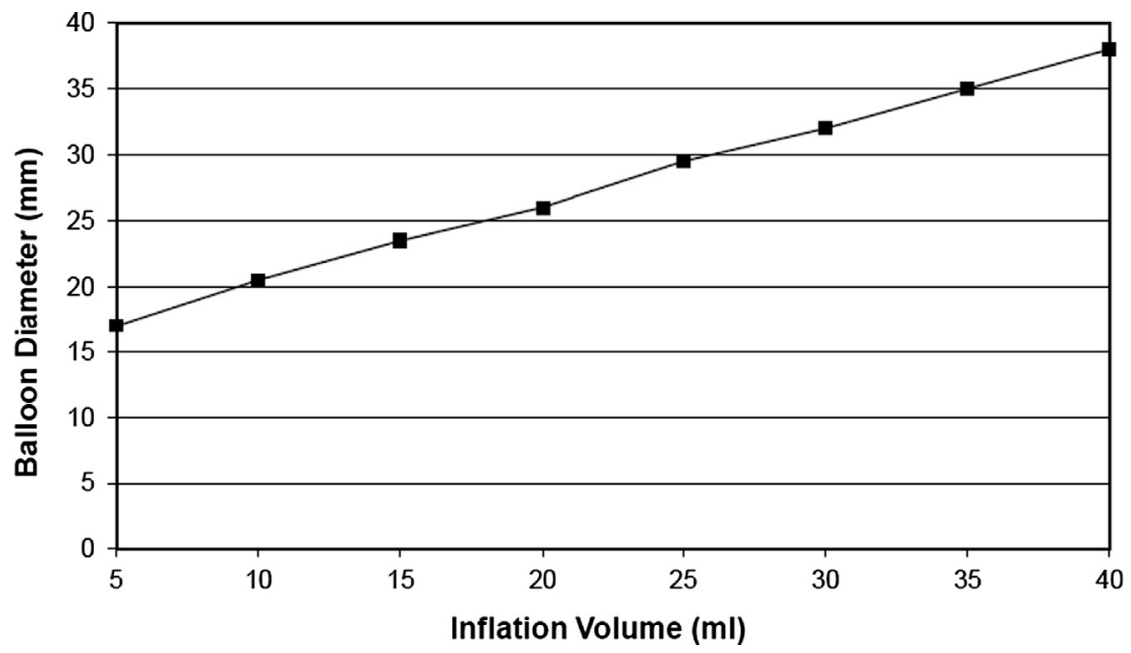

FIGURE 2. In vitro balloon diameter inflation volume curve of the endoaortic catheter. This chart is for reference only, actual diameters may vary. 
tricks on endoaortic balloon clamping in these cases are described. The small dimensions of the aorta and the femoral vessels do not hamper the port-access technique. An accurate preoperative evaluation of the anatomy of the aorto-iliac and femoral arteries is mandatory, especially in these cases.

\section{References}

1. Grossi EA, Loulmet DF, Schwartz CF, Ursomanno P, Zias EA, Dellis SL, et al. Evolution of operative techniques and perfusion strategies for minimally invasive mitral valve repair. J Thorac Cardiovasc Surg. 2012;143:S68-70.
2. Modi P, Rodriguez E, Hargrove WC III, Hassan A, Szeto WY, Chitwood WR Jr Minimally invasive mitral video-assisted mitral valve surgery: a 12-year, 2-center experience in 1178 patients. J Thorac Cardiovasc Surg. 2009;137: 1481-7.

3. Ricci D, Pellegrini C, Aiello M, Alloni A, Cattadori B, D'Armini AM, et al Port-access surgery as elective approach for mitral valve operation in re-do procedures. Eur J Cardiothorac Surg. 2010;37:920-5.

4. Ricci D, Boffini M, Barbero C, El Qarra S, Marchetto G, Rinaldi M. Minimally invasive tricuspid valve surgery in patients at high risk. $J$ Thorac Cardiovasc Surg 2013. Epub ahead of print.

5. Preisman S, Keidan I, Perel A, Mishaly D. Anesthesia for port-access cardiac surgery in a pediatric population. J Cardiothorac Vasc Anesth. 2005;19: 626-9.

\title{
Endoscopic lung abscess drainage with argon plasma coagulation
}

\author{
Eric Goudie, MD, Jordan Kazakov, MD, Claude Poirier, MD, and Moishe Liberman, MD, PhD, Montreal, \\ Quebec, Canada
}

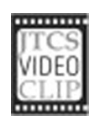

Video clip is available online.

Lung abscesses are most often caused by aspiration of oropharyngeal bacterium. Another cause is airway obstruction. ${ }^{1}$ Antibiotic therapy is the standard treatment approach, but it fails in $10 \%$ to $20 \%$ of cases. ${ }^{2}$ In such cases, alternative therapeutic options usually consist of percutaneous drainage or surgical resection. Endoscopic abscess drainage is another option, but this only has been described in a few case reports and case series.

This case report describes a novel technique for endoscopic lung abscess drainage with argon plasma coagulation. This technique was successfully performed on a patient with limited treatment options.

\section{CLINICAL SUMMARY}

We report the case of a 63-year-old woman who was referred for a left upper lobe (LUL) abscess. Seven years

\footnotetext{
From CHUM Endoscopic Tracheobronchial and Oesophageal Center (CETOC), University of Montreal, Montreal, Quebec, Canada.

Disclosures: Authors have nothing to disclose with regard to commercial support. Received for publication March 3, 2013; revisions received May 10, 2013; accepted for publication May 21, 2013; available ahead of print July 15, 2013.

Address for reprints: Moishe Liberman, MD, PhD, CHUM Endoscopic Tracheobronchial and Oesophageal Center (CETOC), Division of Thoracic Surgery, Centre Hospitalier de l'Université de Montréal, 1560 Rue Sherbrooke E, 8e CD, Pavillon Lachapelle, Bureau D-8051, Montreal, Quebec H2L 4M1, Canada (E-mail: moishe.liberman@umontreal.ca).

J Thorac Cardiovasc Surg 2013;146:e35-7

0022-5223/ $\$ 36.00$

Copyright (c) 2013 by The American Association for Thoracic Surgery http://dx.doi.org/10.1016/j.jtcvs.2013.05.031
}

previously, she had undergone curative intent chemoradiotherapy for LUL squamous cell carcinoma. After treatment, a cavity developed in the LUL, eventually reaching a size of $8.2 \times 4.4 \mathrm{~cm}$ and remaining stable on follow-up computed tomographic scans (Figure 1). Before referral, the patient had received a 1-year course of clarithromycin, rifampin (INN rifampicin), and ethambutol for Mycobacterium avium-intracellulare complex. After treatment, her preantibiotic symptoms of coughing, bronchorrhea, and fever returned, and she reported left pleuritic chest pain. She did not have leukocytosis. Bronchoscopy showed a new and complete obliteration of the left apicoposterior segment bronchus, and bronchoalveolar lavage culture results were negative. The patient was referred for attempt at reopening of the LUL bronchus and endoscopic abscess drainage.

Standard consent was obtained. The patient was placed under general anesthesia. A rigid bronchoscopy was performed, and a therapeutic flexible therapeutic bronchoscope was used through the rigid bronchoscope. A small amount of pus was found in the apical segment of the LUL, with no visible bronchial opening into either the apical or posterior segments. An endobronchial ultrasonographic radial miniprobe was used to confirm the absence of major blood vessels around the bronchus. A 3-mm opening was made to enter the cavity through the apical segment bronchus with a flexible argon plasma coagulation probe. Balloon dilatation was then used to widen the opening to $9 \mathrm{~mm}$. Bleeding was minimal and completely resolved with argon plasma coagulation. A large amount of pus was drained from the cavity, which was inspected and irrigated with saline solution. The cavity opening was left wide open for continuous spontaneous drainage. The procedure was completed in 12 minutes. The patient had postprocedural 